\title{
Timeout and punishment of a single response within a short fixed-ratio schedule of food reinforcement ${ }^{1}$
}

\author{
RALPH W. RICHARDS and MARK \\ RILLING, Michigan State University, East \\ Lansing, Mich. 48823
}

The purpose of the present experiment was to determine if pigeons would obtain timeouts when the 25 th response within a FR 50 schedule of food reinforcement was immediately followed by shock. The location of timeouts within the ratio was also examined. The results suggested that this procedure may result in pigeons obtaining timeouts, although it was not clear as to the important variables underlying this behavior. Ss that did obtain timeouts show'ed a tendency to obtain them early in the ratio on further exposure to the shock.

Recent studies (Azrin, 1961; Thompson, 1964,1965 ) have shown that pigeons and rats will impose periods of extinction (timeouts) when positive reinforcement is delivered under a fixed-ratio schedule. As these tineouts usually occur during the pause after reinforcement, it has been suggested that this portion of the schedule may contain aversive stimuli.

The purpose of the present study was to superimpose the known aversive stimulus electric shock (e.g., Azrin \& Holz, 1966) on a FR 50 schedule of food reinforcement and to determine if timeouts would occur. Specifically, the 25 th response of each ratio was immediately followed by shock. If timeouts did occur, a secondary purpose was to examine their location within the ratio.

Dardano \& Sauerbrunn (1964) showed that if a single response within a FR 50 schedule of food reinforcement was punished, performance was differentially affected depending upon the position of the punished response within the ratio. Punishment of the 25 th response produced unstable responding during the first half of the schedule, while that of the second half was relatively unaffected. Extending their results to the present study, it was hypothesized that if timeouts were obtained they would generally be located before the shock.

Fig. 1. The per cent of session spent in timeout for the three Ss that obtained timeouts. The shock contingencies are presented above each graph. (See Table 1 for details.)

\section{PROCEDURE}

Following the shaping of the key-peck response to the right key, the response requirement for food reinforcement was gradually increased over several sessions, until a FR 50 schedule was established. Sessions usually terminated after $6 \mathrm{~h}$ or 50 reinforcements, whichever occurred first.

For all sessions (except the shaping session), the left key was illuminated. A response to this key produced a 30-sec timeout, during which the chamber was completely dark and all responses were nonfunctional.

The Ss were given a minimum of 25 sessions on the FR 50 without shock. Shock was then delivered immediately after the 25th response of each ratio,

Table 1 Summary of Procedure within the food aperture was illuminated. Reinforcement was $3-\mathrm{sec}$ access to mixed grain; the timing of this interval began when the $S$ placed its head through the aperture, thus interrupting a light beam focused on a photocell. An overhead light provided general illumination.

The shock (from a constant-current shock source) was $.045 \mathrm{sec}$ in duration and was delivered through gold electrodes implanted around the Ss' pubic bones (Azrin, 1959).

Reinforcement and punishment contingencies were programmed by standard electromechanical equipment in an adjacent room. A three-channel printout counter recorded the location of the timeouts within the ratio. A cumulative recorder and several standard counters were also used.

\begin{tabular}{lc} 
Condition & $\begin{array}{c}\text { Number } \\
\text { of Sessions }\end{array}$ \\
No Shock & 40 \\
$12 \mathrm{~mA}$ & 12 \\
$8 \mathrm{~mA}$ & 16 \\
No Shock & 8 \\
$12 \mathrm{~mA}$ & 10 \\
No Shock & 40 \\
$12 \mathrm{~mA}$ & 22 \\
No Shock & 16 \\
$8 \mathrm{~mA}$ & 9 \\
No Shock & 25 \\
$2 \rightarrow 12 \mathrm{~mA}$ & 1 \\
$12 \mathrm{~mA}$ & 25 \\
No Shock & 25 \\
$2 \rightarrow 12 \mathrm{~mA} *$ & 1 \\
$15 \mathrm{~mA}$ & 1 \\
$17 \mathrm{~mA}$ & 25 \\
\hline
\end{tabular}

- Intensity increased in steps of $2 \mathrm{~mA}$

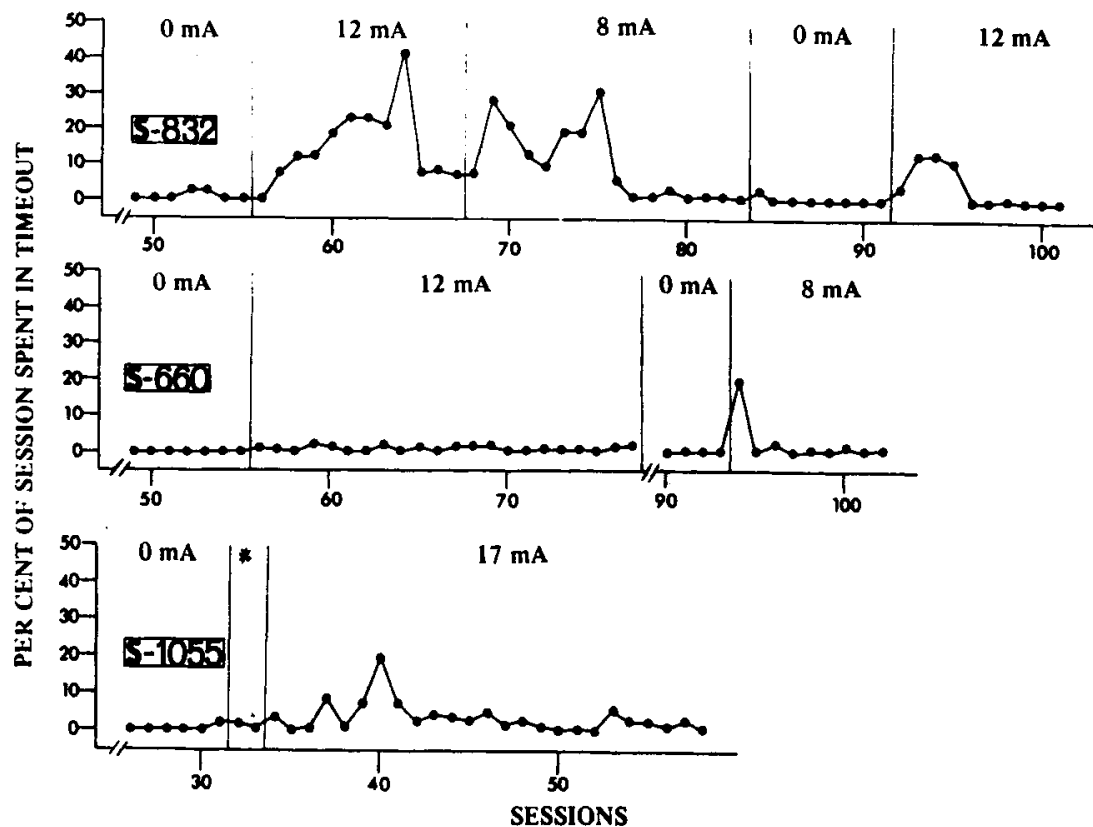




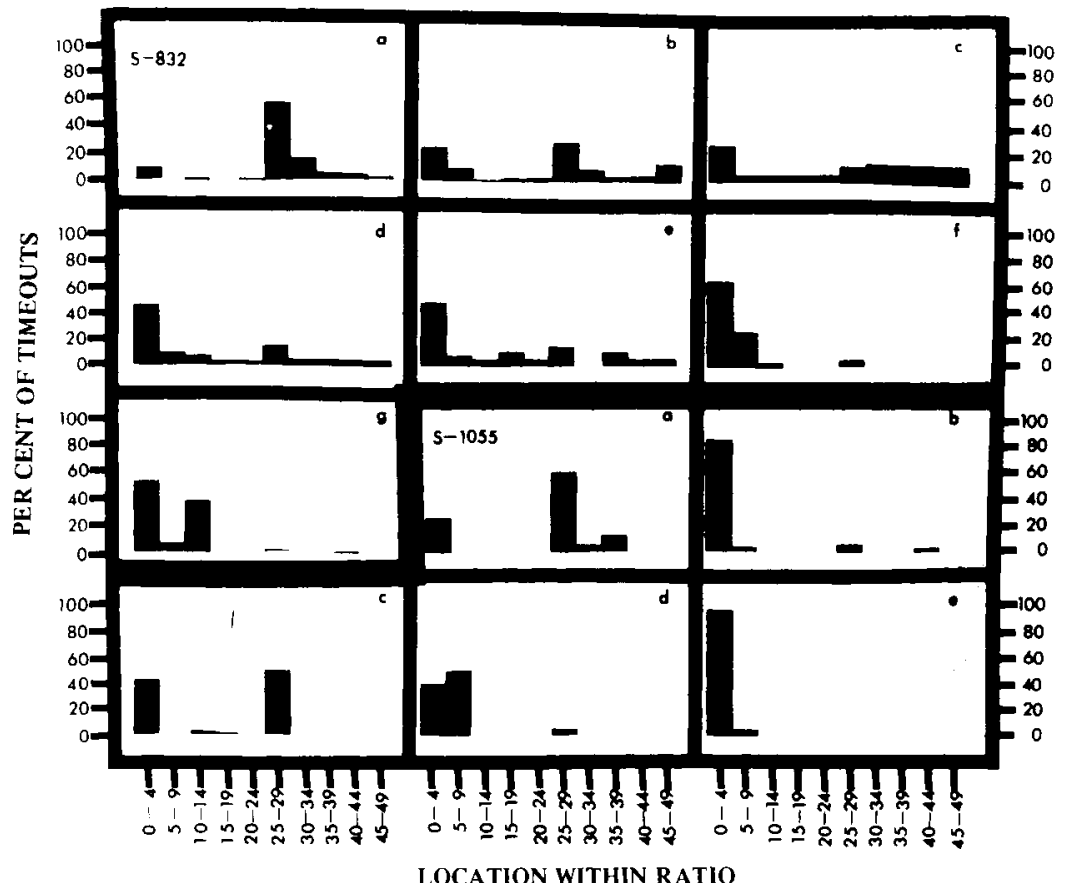

regardless of any timeouts obtained. In an attempt to produce continued responding on the food key and stable time-out behavior, two methods of introducing the shock and several shock intensities were used. These details are presented in Table 1.

\section{RESULTS AND DISCUSSION}

Figure 1 shows the per cent of each session spent in timeout for S 832, S 660 , and $S$ 1055. S 440 obtained no timeouts during the 25 sessions of the $12.0-\mathrm{mA}$ shock. It is clear from this figure that only S 832 and S 1055 spent any appreciable time in timeout.

While it appears that under some conditions pigeons may obtain timeouts from shock, the large inter- and intra-S variability make any conclusion at this time unwarranted. Variables of importance may include shock intensity and the degree of accompanying response suppression (on the food key). With responding almost completely suppressed, S 660 obtained few timeouts. In general, S 832 maintained responding and many timeouts were obtained. However, during Sessions 65 and $67, \mathrm{~S} 832$ made no responses on the food key and few timeouts were obtained. For Sessions 68-83, the shock intensity was reduced to $8.0 \mathrm{~mA}$, and responding to both the food key and the timeout key increased. Unfortunately, the per cent of each session spent in timeout varied and eventually decreased to zero. While Hearst \& Sidman (1962), Hearst (1963, 1967), and Hearst \& Koresko (1964) were able to manipulate shock intensity in order to maintain time-out behavior in rats, the present Es were unable to duplicate this with pigeons. There are, however, several procedural differences that might account for this.

Although the present study gives no definitive explanation for this decrease in timeouts or its absence in some Ss, important factors may be the method of introducing the shock and adaptation to shock (Azrin, Holz, \& Hake, 1963), the acquisition of discriminative properties by the shock (Holz \& Azrin, 1961; Dardano \& Sauerbrunn, 1964), and the fixed duration of the timeout (Zimmerman \& Ferster, 1964).

The data concerning the location of the timeouts within the ratio show a more consistent relationship. S 832 obtained 39 timeouts during the 40 sessions of FR 50 without shock. All of these timeouts occurred during the pause after reinforcement. S 1055 took 189 timeouts during the 23 sessions of the FR 50 without shock (two sessions are excluded due to apparatus failure); 147 of these were during the pause after reinforcement. For the last 18 sessions on the FR 50 without shock, 123 of the 129 timeouts occurred during the pause after reinforcement. These results are in general agreement with those of Azrin (1961) and Thompson $(1964,1965)$.

Figure 2 is a series of histograms showing the location of the timeouts within the ratio for S 832 and S 1055 Each histogram was computed from five sessions of shock, irrespective of the specific shock intensities used. Histogram a for S 832 shows that on the initial
Fig. 2. The location of the timeouts (in blocks of five responses) within the FR 50 . Only timeouts from completed ratios were used in forming this figure.

exposure to shock most timeouts occurred between Responses 25 and 29 (i.c., almost immediately after the shock). On further exposure (Histograms b-e). timeouts began to occur frequently at all locations within the ratio and the per cent occurring immediately after the shock decreased. Eventually (Histograms f and g), timeouts rarely occurred after the shock, and their most frequent location was during the early portion of the ratio. The change in timeout location is less clear for S 1055 . but it is clear that during Histogram e most timeouts were obtained early in the ratio.

While the data from S 832 and S 1055 may not be directly comparable due to differences in shock intensities and manner of shock introduction, it is clear that with further exposure to shock, timeouts were generally obtained before the shock and most often early in the ratio. The results seem to suggest thit, following extended training on the present procedure, the termination of reinforcement functions as a discriminative stimulus for the occurrence of the shock and time-out behavior. But the occurrence of the shock, itself, also functions as a discriminative stimulus for nonshock within the remaining portion of the ratio. Hence, the $S$ responds at a rapid rate on the food key until reinforcement is obtained (cf. Dardano \& Sauerbrunn, 1964).

\section{REFERENCFS}

AZRIN, N. H. A technique for delivering shock to pigeons. Journal of the Fxperimental Analysis of Behavior, 1959.2, 161-163.

AZRIN, N. H. Timeout from positive reinforcement. Science, 1961, 133, 382-383. AZRIN, N. H., \& HOLZ, W. C. Punishment. In W. K. Honig (Ed.), Operant behavior: Areas of research and application. New York: Appleton-Century-Crofts, 1966. Pp. 380-447.

DARDANO, J. F., \& SAUIERBRUNN, D. Selective punishment of fixed-ratio performance. Journal of the Experimental Analysis of Behavior, 1964, 7, 255-260.

HEARST, E. Escape from a stimulus associated with both reward and punishment. Journal of Comparative \& Physiological Psychology, $1963,56,1027-1031$.

HEARST, E. Oscillatory behavior during approach-avoidance conflict. Journal of the Experimental Analysis of Behavior, 1967, 10, 75-84.

HEARST, E., \& KORESKO, M. B. Self-presentation and self-termination of a conflict-producing stimulus. Science, 1964. $146,415-416$.

HEARST, E., \& SIDMAN, M. Some behavioral effects of a concurrently positive and negative stimulus. Journal of the Experimental Analysis of Behavior, 1961, 4, 251-256.

HOLZ, W. C., \& AZRIN, N. H. Discriminative properties of punishment. Journal of the Experimental Analysis of Behavior, 1961, 4, 225-232. 
THOMPSON, D. M. Escape from $S^{D}$ associated with fixed-ratio reinforcement. Journal of the Experimental Analysis of Behavior, 1964, 7, 1-8.

THOMPSON, D. M. Time-out from fixed-ratio reinforcement: A systematic replication. Psychonomic Science, 1965, 2, 109-110.

ZIMMERMAN, J., \& FERSTER, D. B. Somc notes on timeout from reinforcement. Journal of the Experimental Analysis of Behavior, $1964,7,13-19$.

NOTE

1. This research was supported in part by PHS Research Grant No. 5R01 MH13343 from the National Institute of Mental Health.

\section{Foot-thumping in the gerbil: The effect of establishing a home cage ${ }^{1}$}

\begin{abstract}
CHRIS SPATZ ${ }^{2}$ and WILLIAM R. GRANGER, ${ }^{3}$ The University of the South, Sewanee, Tenn. 37375
\end{abstract}

In experiments with gerbils (Meriones unguiculatus) it was shown that length of home cage residence affects the probability of foot-thumping and that foot-thumping is significantly reduced in another gerbil's vacant home cage. General excitement or arousal seems to be the factor common to the situations in which gerbils foot-thump. Two possible functional interpretations were suggested.

Gerbils (Meriones unguiculatus) foot-thump by rhythmically hitting both hind feet against the floor simultaneously. The thumps are usually grouped by twos although there are occasional bursts of three or more. Gerbils foot-thump in a variety of situations, e.g., during sexual intercourse (Kuehn \& Zucker, 1968) and when shocked on the feet or given rewarding brain stimulation (Routtenberg \& Kramis, 1967; Kramis \& Routtenberg, 1969). We have found that gerbils foot-thump after being handled and dropped back into their home cage. During incidental observations, it was noted that gerbils did not foot-thump when dropped into a fresh cage. It was the purpose of these experiments to determine the relation of foot-thumping to the length of home cage residence.

\section{Experiment 1}

Subjects

The Ss were 12 adult male gerbils, about 4 months old, which were housed in $17.5 \times 24.5 \times 16 \mathrm{~cm}$ laboratory cages. The covers were hardware cloth and the plywood floors were covered with wood shavings. Food and water were available ad lib.

$$
\text { Design }
$$

Six periods of home cage residence were used: 0,20 , and $60 \mathrm{~min}$ and 24,48 , and $168 \mathrm{~h}$. Each $\mathrm{S}$ was tested in all six conditions. Two 6 by 6 Latin squares were used to determine the order of the conditions in which Ss served. No $S$ ever lived in the same cage twice. Ss were not tested more than once in a single day. Testing started at noon each day.

\section{Procedure}

An $S$ was placed into a cage with fresh wood shavings and was not disturbed for the prescribed period of home cage residence. At the end of the period, $S$ was picked up, stroked on the back for $15 \mathrm{sec}$, and dropped $18 \mathrm{~cm}$ ( 7 in.) back into the cage and observed for $2 \mathrm{~min}$. Latency and duration of any foot-thumping were recorded.

\section{Results}

The number of Ss that foot-thumped for each length of home cage residence is shown in Fig. 1. The greater the length of home cage residence, the greater the probability of foot-thumping. A Subjects/Groups by Repeated Measures analysis of variance on the duration scores, including zeros, produced a length of residence main effect that was significant $[F(5,30)=3.83, \quad p<.01]$. Neither the order of testing main effect or the interaction was significant. The mean duration of a foot-thumping session was $5.9 \mathrm{sec}, \mathrm{SD}=5.2 \mathrm{sec}$. The latency measures showed no systematic trend. The mean latency over all conditions was $3.1 \mathrm{sec}$, $\mathrm{SD}=2.6 \mathrm{sec}$.

\section{Experiment 2}

Experiment 2 was designed to assess the effect of daily handling and to replicate the procedures of Experiment 1.

Subjects and Procedures

Twelve adult male gerbils, about 7 months old, served as Ss. The conditions of housing, food and water supply, handling, and the $E$ were the same as in Experiment 1 .

\section{Design}

Experiment 2 extended over 13 days. All the Ss were tested on Day 1 in fresh cages. Ss 1.6 were then tested every day for 6 more days. Ss 7-12 were not handled during this period. On Day 7, all Ss were tested. On Day 8 , all Ss were tested in a fresh cage. Ss 7-12 were then tested every day for 7 more days, at which time all Ss were again tested. Thus, each $S$ served in the daily handled condition and the weekly handled condition. Again, testing started at noon.

\section{Results}

The main results for Experiment 2 are summarized in Table 1. A dependent-measures $t$ test comparing the duration scores after 1 week of daily handling or weekly handling was not significant, $\mathrm{t}, 11 \mathrm{df}=1.00, \mathrm{p}>.15$. There appear to be no systematic effects of handling on foot-thumping. The main difference between the results of Experiment 1 and Experiment 2 is that fewer Ss foot-thumped in the second experiment. However, as in Experiment 1, the greater the length of home cage residence, the greater the probability of foot-thumping.

\section{DISCUSSION}

General excitement or arousal seems to be the factor common to the diverse situations in which gerbils foot-thump. The present data are most simply explained by assuming that stroking and dropping produce sufficient excitement, but that a novel environment evokes responses incompatible with foot-thumping, e.g., responses connected with exploration.

As for functional significance, foot-thumping may serve as territorial behavior, as gerbils foot-thump in their home environments. In order to be sure that foot-thumping is related to home cage residence, it is necessary to show that the gerbils in Experiments 1 and 2 were responding to cues specific to their own cage and not to cues associated with any gerbil's cage. If the gerbils were responding to cues specific to their own cage, they should not foot-thump when dropped into the vacant cage of another gerbil. In order to test this, a preliminary experiment was

Table 1

Number of Gerbils that Foot-Thumped in Experiment 2

\begin{tabular}{|c|c|c|}
\hline & \multicolumn{2}{|c|}{$\begin{array}{c}\text { Length of } \\
\text { Cage Residence. }\end{array}$} \\
\hline & $0 \mathrm{Min}$ & 1 Week \\
\hline $\begin{array}{l}\text { Daily Handling } \\
\text { and Testing } \\
\mathrm{N}=24\end{array}$ & 0 & 7 \\
\hline $\begin{array}{l}\text { Weckly Handling } \\
\text { and Testing } \\
\mathrm{N}=24\end{array}$ & 1 & 9 \\
\hline
\end{tabular}

